Western University

Scholarship@Western

2019

Polyglyoxylamides: Tuning Structure and Properties of SelfImmolative Polymers

Quinton E.A. Sirianni

Western University

Amir Rabiee Kenaree

Western University

Elizabeth Gillies

Western University, egillie@uwo.ca

Follow this and additional works at: https://ir.lib.uwo.ca/chempub

Part of the Chemistry Commons

Citation of this paper:

Sirianni, Quinton E.A.; Rabiee Kenaree, Amir; and Gillies, Elizabeth, "Polyglyoxylamides: Tuning Structure and Properties of Self- Immolative Polymers" (2019). Chemistry Publications. 132.

https://ir.lib.uwo.ca/chempub/132 


\title{
Polyglyoxylamides: Tuning Structure and Properties of Self-
}

\section{Immolative Polymers}

Quinton E. A. Sirianni, ${ }^{\dagger}$ Amir Rabiee Kenaree, ${ }^{\dagger}$ and Elizabeth R. Gillies ${ }^{* *}$

Department of Chemistry and the Centre for Advanced Materials and Biomaterials Research, The University of Western Ontario, 1151 Richmond St., London, Ontario, Canada, N6A 5B7.

Department of Chemical and Biochemical Engineering, The University of Western Ontario, 1151 Richmond St., London, Ontario, Canada, N6A 5B9.

For "Table of Contents" use only

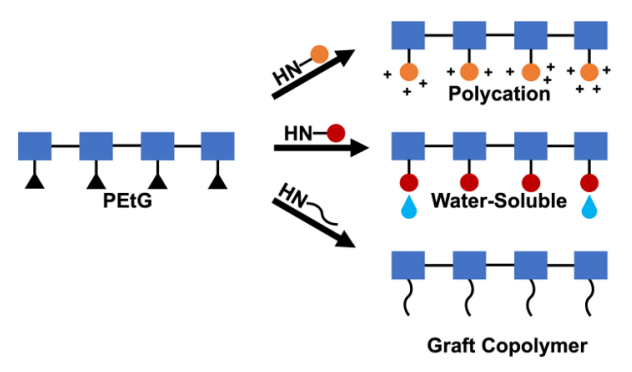

\begin{abstract}
Self-immolative polymers (SIPs) are a class of stimuli-responsive materials that undergo controlled end-to-end depolymerization in response to stimuli. Their unique degradation and amplification properties have made them of interest for a diverse array of applications including sensors, vehicles for controlled release, and transient objects. Thus far, a limited number of SIP backbones exists, each with its own advantages and limitations. We report here the preparation and study of polyglyoxylamides (PGAms) as a new class of SIPs. PGAms were synthesized by simple post-polymerization modifications of poly(ethyl glyoxylate) (PEtG). While retaining the important stimuli-responsive depolymerization properties of polyglyoxylates, PGAms exhibited
\end{abstract}


much different thermal properties, and some were even water-soluble. Furthermore, a depolymerizable PGAm analogue of poly(ethylene glycol) was prepared, demonstrating the capability to synthesize more complex PGAm graft copolymers. Overall, PGAms are a new class of SIPs with unique combinations of physical, thermal, and degradative properties that provide avenues for novel applications.

\section{Introduction}

Stimuli-responsive polymers are a class of materials that can undergo changes in their physical or chemical properties when exposed to specific stimuli. They have been explored for a wide range of applications from smart coatings to drug delivery systems. ${ }^{1-4}$ For example, thermo-responsive polymers such as poly( $N$-isopropylacrylamide) undergo entropically-driven aggregation and precipitation above their lower critical solution temperatures. ${ }^{5}$ This property has been exploited for the development of hydrogel valves in microfluidic channels ${ }^{6}$ and for the controlled release of drugs. $^{7-8}$ In other cases, stimuli lead to polymer degradation. For example, polyacetals undergo selective degradation at acidic $\mathrm{pH}$. Various polyacetals have been reported ${ }^{9-11}$ and have shown promise for targeted drug delivery in vivo.

Self-immolative polymers (SIPs) are a recently developed subset of stimuli-responsive degradable polymers that undergo end-to-end depolymerization in response to stimuli. Most SIPs possess stabilizing end-caps at their termini that can be cleaved off by specific stimuli. Cleavage initiates a cascade of reactions resulting in the conversion of the polymer into small molecules (Figure 1a-c). ${ }^{12}$ Since their introduction in $2008,{ }^{13}$ significant developments have been reported including the introduction of backbones such as polycarbamates, ${ }^{13-14}$ poly(benzyl ether)s, ${ }^{15}$ and polyacetals $^{16-17}$ that depolymerize by different mechanisms such as eliminations, ${ }^{13}, 15$ 
cyclizations, ${ }^{18}$ combinations of eliminations and cyclizations, ${ }^{14,19}$ or based on low polymer ceiling temperatures. ${ }^{16-17}$ Additionally, various end-caps have been incorporated onto SIPs, enabling their depolymerization to be initiated by different stimuli including light,,${ }^{20-21}$ heat, ${ }^{22-23}$ changes in redox $^{21,24-25}$ or $\mathrm{pH}^{25-26}$ conditions, and in response to the activity of specific enzymes. ${ }^{13,} 27$ Furthermore, the utility of SIPs in applications such as transient plastics, ${ }^{16,}{ }^{28}$ degradable microcapsules, ${ }^{26,29}$ drug delivery vehicles, ${ }^{21,30-32}$ microscale pumps, ${ }^{33}$ and sensors ${ }^{34-38}$ has been demonstrated.

a)

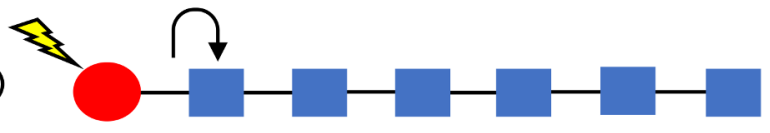

b)

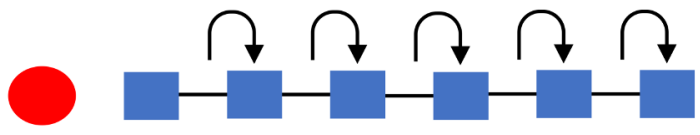

c)

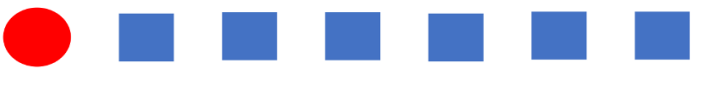

Stimulus

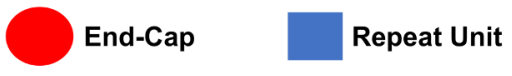

d)


Figure 1. a) SIPs are stabilized with an end-cap that can be cleaved off in the presence of a particular stimulus; b) Removal of the end-cap leads to a cascade depolymerization of the polymer chain; c) The depolymerization products include the end-cap and repeat units of the polymer, which may be the original monomers or derivative products depending on the depolymerization mechanism; d) A polyglyoxylamide depolymerizes upon cleavage of the end-cap (Init = polymerization initiator; $\mathrm{EC}=$ end-cap). 
Our group reported polyglyoxylates as a class of SIPs. ${ }^{17}$ Polyglyoxylates have advantages including their preparation from commercially available monomers or monomers that can be synthesized from readily available precursors such as fumaric or maleic acid. In addition, the depolymerization product glyoxylic acid hydrate is an intermediate in the glyoxylic acid cycle and is non-harmful to the environment. ${ }^{39}$ Based on their properties and depolymerization behaviour, polyglyoxylates are finding applications in areas such as smart coatings ${ }^{38,40}$ and drug delivery vehicles. ${ }^{30-32}$ Polyglyoxylates inherently have pendant ester groups at each repeat unit, and the eventual hydrolysis of these esters reveals carboxylic acids that can intramolecularly catalyze backbone acetal hydrolysis, leading to depolymerization. Thus, polyglyoxylates have a limited lifetime even in their non-triggered state, which can be advantage or limitation depending on the application. All of the previously reported polyglyoxylates have been insoluble in water. ${ }^{17,32,39,41-}$ 42

The replacement of the ester pendant groups of polyglyoxylates with amides should slow side chain hydrolysis, stabilizing the polymers in their untriggered state, while at the same time yielding polymers with different physical and thermal properties that are capable of triggered endto-end depolymerization (Figure 1d). Thus, we report here the syntheses of polyglyoxylamides (PGAms), a new class of SIPs. Several different amines were used to prepare PGAms from poly(ethyl glyoxylate) (PEtG) using mild post-polymerization modification conditions to provide an array of new properties and functions while retaining the abilities of the polymers to depolymerize in response to stimuli. For example, relative to $25^{\circ} \mathrm{C}$, the highest glass transition temperature $\left(\mathrm{T}_{\mathrm{g}}\right)$ reported for a polyglyoxylate, ${ }^{17}$ the measured $\mathrm{T}_{\mathrm{g}}$ values of the studied PGAms ranged from $39-90{ }^{\circ} \mathrm{C}$. Additionally, several of the new PGAms demonstrated water-solubility. 
Finally, using amine-terminated oligo(ethylene glycol) (OEG), a PGAm analogue of poly(oligo(ethylene glycol methyl ether) methacrylate) (POEGMA), a graft copolymer analogue of poly(ethylene glycol) (PEG) that exhibits the favorable stealthy properties of $\mathrm{PEG},{ }^{43}$ was synthesized.

\section{Experimental}

General procedures and additional procedures are provided in the supporting information.

\section{Synthesis of PGAm-NMe-MMT (Representative Polyglyoxylamide Synthesis). PEtG-MMT}

(2.1 g) was placed in a round-bottom flask and stoppered with a rubber septum. The flask was evacuated. After charging the flask with nitrogen at atmospheric pressure, $21 \mathrm{~mL}$ of dry 1,4dioxane was injected to give a $100 \mathrm{mg} / \mathrm{mL}$ polymer stock solution. From this solution, an aliquot was removed $(2.5 \mathrm{~mL}, 250 \mathrm{mg}$ of polymer, $2.4 \mathrm{mmol}$ of ester, 1.0 equiv.) and placed into a flamedried Schlenk flask filled with nitrogen at atmospheric pressure. An aliquot of methylamine solution ( $6.5 \mathrm{~mL}, 13 \mathrm{mmol}, 5.4$ equiv.) was then added to the flask. The flask was closed off from the nitrogen line and the reaction mixture was stirred for $48 \mathrm{~h}$. Removal of the solvent, ethanol, and unreacted amine under vacuum gave the crude product. This product was subsequently purified by dissolution in minimal $\mathrm{CH}_{2} \mathrm{Cl}_{2}$ and precipitation in $100 \mathrm{~mL}$ of $n$-pentane. After decanting the liquid, the precipitate was dried under vacuum to afford $210 \mathrm{mg}$ of an off-white powder. Yield: 98\%. ${ }^{1} \mathrm{H}$ NMR $\left(\mathrm{CDCl}_{3}, 400 \mathrm{MHz}\right): \delta 7.67-8.64(\mathrm{~m}, 1 \mathrm{H}), 5.73(\mathrm{~s}, 1 \mathrm{H}), 2.79(\mathrm{~s}, 3 \mathrm{H})$. ${ }^{13} \mathrm{C}\left\{{ }^{1} \mathrm{H}\right\}$ NMR $\left(\mathrm{CDCl}_{3}, 100 \mathrm{MHz}\right): \delta 166.3-169.0,94.7-98.9,26.3$. FT-IR: 3294, 3098, 2942, $1663,1543 \mathrm{~cm}^{-1}$. SEC (DMF, PMMA): $\mathrm{M}_{\mathrm{n}}=54.1 \mathrm{~kg} / \mathrm{mol}, \mathrm{M}_{\mathrm{w}}=77.6 \mathrm{~kg} / \mathrm{mol}, \nexists=1.4 . \mathrm{T}_{\mathrm{g}}=90^{\circ} \mathrm{C}$. 
Depolymerization of PGAm-MMTs. PGAm-NEt-MMT, PGAm-NnPr-MMT, PGAm-NiPrMMT, and PGAm-Pyrr-MMT were each dissolved in $1.1 \mathrm{~mL}$ of 9:1 $\mathrm{CD}_{3} \mathrm{CN}: \mathrm{D}_{2} \mathrm{O}$. PGAm-NMeMMT and PGAm-DMAE-MMT were each dissolved in $1.1 \mathrm{~mL}$ of 9:1 $\mathrm{D}_{2} \mathrm{O}: \mathrm{CD}_{3} \mathrm{CN}$. All polymer solutions were $1 \% \mathrm{w} / \mathrm{v}$ in concentration. Each solution was separated into two $550 \mu \mathrm{L}$ aliquots, which were each placed into an NMR tube. In one of the two aliquots, $30 \mu \mathrm{L}$ of glacial acetic acid was added to give a $0.9 \mathrm{M}$ concentration of acid. No acid was added to the second aliquot (control). The NMR tubes were promptly sealed and stored at room temperature. Depolymerization was monitored by acquiring ${ }^{1} \mathrm{H}$ NMR spectra of the samples at specific time points and examining the integration ratios between the peaks corresponding to the polymer backbone methine protons at $\sim 5.5-5.6 \mathrm{ppm}$ and the methine proton of the monomer hydrate (depolymerization product) at $\sim 5.0-$ $5.3 \mathrm{ppm}$.

Depolymerization of PGAm-Ts. A 0.1 M deuterated citrate buffer was prepared by dissolving $190 \mathrm{mg}$ of citric acid into $10 \mathrm{~mL}$ of $\mathrm{D}_{2} \mathrm{O}$ and correcting the $\mathrm{pH}$ to 3.0 using $\mathrm{NaOH}$. A $0.1 \mathrm{M}$ deuterated phosphate buffer was prepared by dissolving $52 \mathrm{mg}$ of $\mathrm{KH}_{2} \mathrm{PO}_{4}$ and $110 \mathrm{mg}$ of $\mathrm{K}_{2} \mathrm{HPO}_{4}$ into $10 \mathrm{~mL}$ of $\mathrm{D}_{2} \mathrm{O}$ and correcting the $\mathrm{pH}$ to 7.4 with $\mathrm{KOH}$. PGAm-NMe-T, PGAm-DMAE-T, and PGAm-Pyrr-T were each dissolved in $600 \mu \mathrm{L}$ of the $\mathrm{pH} 3.0$ buffer. Additionally, the polymers were each dissolved in $600 \mu \mathrm{L}$ of the $\mathrm{pH} 7.4$ buffer. All polymer solutions were $1 \% \mathrm{w} / \mathrm{v}$ in concentration. Each solution was placed into an NMR tube and the tubes were promptly sealed and stored at room temperature. Depolymerization was monitored by acquiring ${ }^{1} \mathrm{H}$ NMR spectra of the samples at specific time points and examining the integration ratios between the polymer backbone methine protons at $\sim 5.5-5.6 \mathrm{ppm}$ and the methine proton of monomer hydrate (depolymerization product) at $\sim 5.3-5.5 \mathrm{ppm}$. 
Synthesis of PGAm-OEG-T. PEtG-T (210 mg of polymer, $2.1 \mathrm{mmol}$ of ester, 1.0 equiv.) was dissolved in a pressure tube using $10 \mathrm{~mL}$ of dry 1,4-dioxane. OEG-NH 2 (1.2 g, $2.5 \mathrm{mmol}, 1.0$ equiv.) was subsequently added and the flask was capped. The reaction mixture was then heated at $60{ }^{\circ} \mathrm{C}$ for 9 days. The solution was concentrated, dissolved in $10 \mathrm{~mL}$ of $\mathrm{CHCl}_{3}$, precipitated into $100 \mathrm{~mL}$ of $\mathrm{Et}_{2} \mathrm{O}$, and stirred for $20 \mathrm{~min}$ before allowing the precipitate to settle. The solvent was then decanted off and the purification procedure was repeated two times. The precipitate was then dried under vacuum to afford $720 \mathrm{mg}$ of the product. Yield $=57 \% .{ }^{1} \mathrm{H} \mathrm{NMR}\left(\mathrm{CDCl}_{3}, 400 \mathrm{MHz}\right): \delta$ 7.62-8.70 (m, 100H), 7.37-7.45 (s, 12H), 7.13-7.37 (m, 202H) 5.67 (s, 88H), 3.11-3.93 (m, 4270H). ${ }^{13} \mathrm{C}\left\{{ }^{1} \mathrm{H}\right\}$ NMR $\left(\left(\mathrm{CD}_{3}\right)_{2} \mathrm{SO}, 100 \mathrm{MHz}\right): \delta 71.3,69.8,58.0$. FT-IR: 3392, 2877, 1652, $1559 \mathrm{~cm}^{-1}$. SEC (DMF, PMMA): $\mathrm{M}_{\mathrm{n}}=58.5 \mathrm{~kg} / \mathrm{mol}, \mathrm{M}_{\mathrm{w}}=97.4 \mathrm{~kg} / \mathrm{mol}, \oslash=1.7 . \mathrm{T}_{\mathrm{m}}=23{ }^{\circ} \mathrm{C}$.

Depolymerization of PGAm-OEG-T. PGAm-OEG-T was dissolved at $1 \% \mathrm{w} / \mathrm{v}$ at $\mathrm{pH} 3.0$ and pH 7.4 and depolymerization was monitored by ${ }^{1} \mathrm{H}$ NMR spectroscopy using the deuterated buffers and techniques described above in "Depolymerization of PGAm-Ts". Additionally, PGAm-OEGT was dissolved in $5.0 \mathrm{~mL}$ of each buffer to create $0.5 \% \mathrm{w} / \mathrm{v}$ solutions at $\mathrm{pH} 3.0$ and $\mathrm{pH} 7.4$. These solutions were promptly sealed in vials and stored at room temperature. At specified time points, $300 \mu \mathrm{L}$ of the solution was removed, filtered, and then directly injected for analysis by aqueous SEC. The chromatograms were monitored for changes in the polymer elution time and refractive index intensity over time.

\section{Results and Discussion}

Synthetic Approaches to Polyglyoxylamides. There are two potential approaches for synthesizing PGAms (Scheme 1). The first is the monomer polymerization approach, where 
glyoxylamide monomers are synthesized and purified before being polymerized. While ensuring amide moieties at each repeat unit, the limitation of this approach is that each unique glyoxylamide would need to be synthesized and purified independently. The second approach to synthesize PGAms is the post-polymerization modification of polyglyoxylates. This approach has several advantages including the ease of synthesis of the PEtG precursor from commercially available monomer, the one-step amidation reaction of PEtG, and the ability to create a small library of different PGAms from a single batch of PEtG, allowing all of the PGAms to have the same degree of polymerization $\left(\mathrm{DP}_{\mathrm{n}}\right)$ for structure-property comparisons. Post-polymerization modification by amidation has been noted to be an effective method when used to replace ester pendant groups on polymers. ${ }^{44}$ Therefore, to synthesize self-immolative PGAms for study, post-polymerization modification was pursued.

Monomer Polymerization Approach

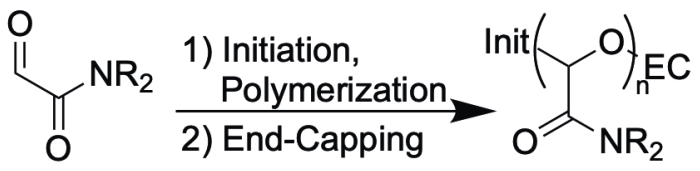

Glyoxylamide Polyglyoxylamide

\section{Post-Polymerization Modification Approach}

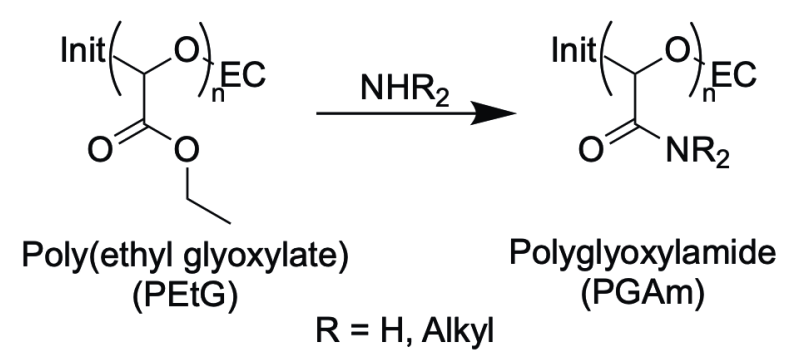

Scheme 1. Synthetic approaches for obtaining PGAms.

\section{Synthesis of 4-Monomethoxytrityl End-Capped PEtG for Post-Polymerization Modification.}

To synthesize different PGAms via post-polymerization modification, a PEtG precursor with an 
appropriate stimuli-responsive end-cap was needed. First, PEtG with a 4-monomethoxytrityl endcap (PEtG-MMT) was targeted (Scheme 2). This end-cap was selected because prior work has shown it to serve as an acid-sensitive end-cap for $\mathrm{PEtG}^{25}$ In addition, unlike many other reported end-caps that are conjugated to the PEtG terminus by a carbonate or carbamate linkage, ${ }^{17,25,30}$ the trityl moiety connects to the polymer via an ether linkage. An ether linkage is not susceptible to cleavage in the post-polymerization modification conditions as it does not possess a carbonyl moiety for nucleophilic attack by the amines.

PEtG-MMT was synthesized by a modified version of our previously reported method (Scheme 2). ${ }^{45} n$-Butyl lithium was used to initiate an anionic polymerization of ethyl glyoxylate in toluene at $-20{ }^{\circ} \mathrm{C}$. In addition to 4-monomethoxytrityl chloride as an end-cap and triethylamine $\left(\mathrm{NEt}_{3}\right), \mathrm{AgNO}_{3}$ was added as $\mathrm{Ag}^{+}$can scavenge $\mathrm{Cl}^{-}$ions, thereby enhancing the end-capping yield. Purification resulted in a colourless tacky solid. Analysis by ${ }^{1} \mathrm{H}$ NMR, ${ }^{13} \mathrm{C}$ NMR, and FT-IR spectroscopic methods confirmed the structure of the polymer by comparison with previous reports (Figures S1, S15, and S29). ${ }^{17,25}$ Size-exclusion chromatography (SEC) in $N, N$-dimethylformamide (DMF) relative to poly(methyl methacrylate) (PMMA) standards suggested that PEtG-MMT had a number average molar mass $\left(\mathrm{M}_{\mathrm{n}}\right)$ of $51.8 \mathrm{~kg} / \mathrm{mol}$ and a dispersity $(\nexists)$ of 1.4 . Because of the polymer's high molar mass, end-group analysis by ${ }^{1} \mathrm{H}$ NMR spectroscopy could not be used to determine the $\mathrm{DP}_{\mathrm{n}}$ of the PEt-MMT or any of the PGAms subsequently synthesized from it. However, thermogravimetric analysis (TGA) confirmed that the polymer was effectively endcapped as it was stable to $170{ }^{\circ} \mathrm{C}$, whereas uncapped PEtG was previously demonstrated to degrade at $84{ }^{\circ} \mathrm{C}$ during TGA. ${ }^{17}$ 


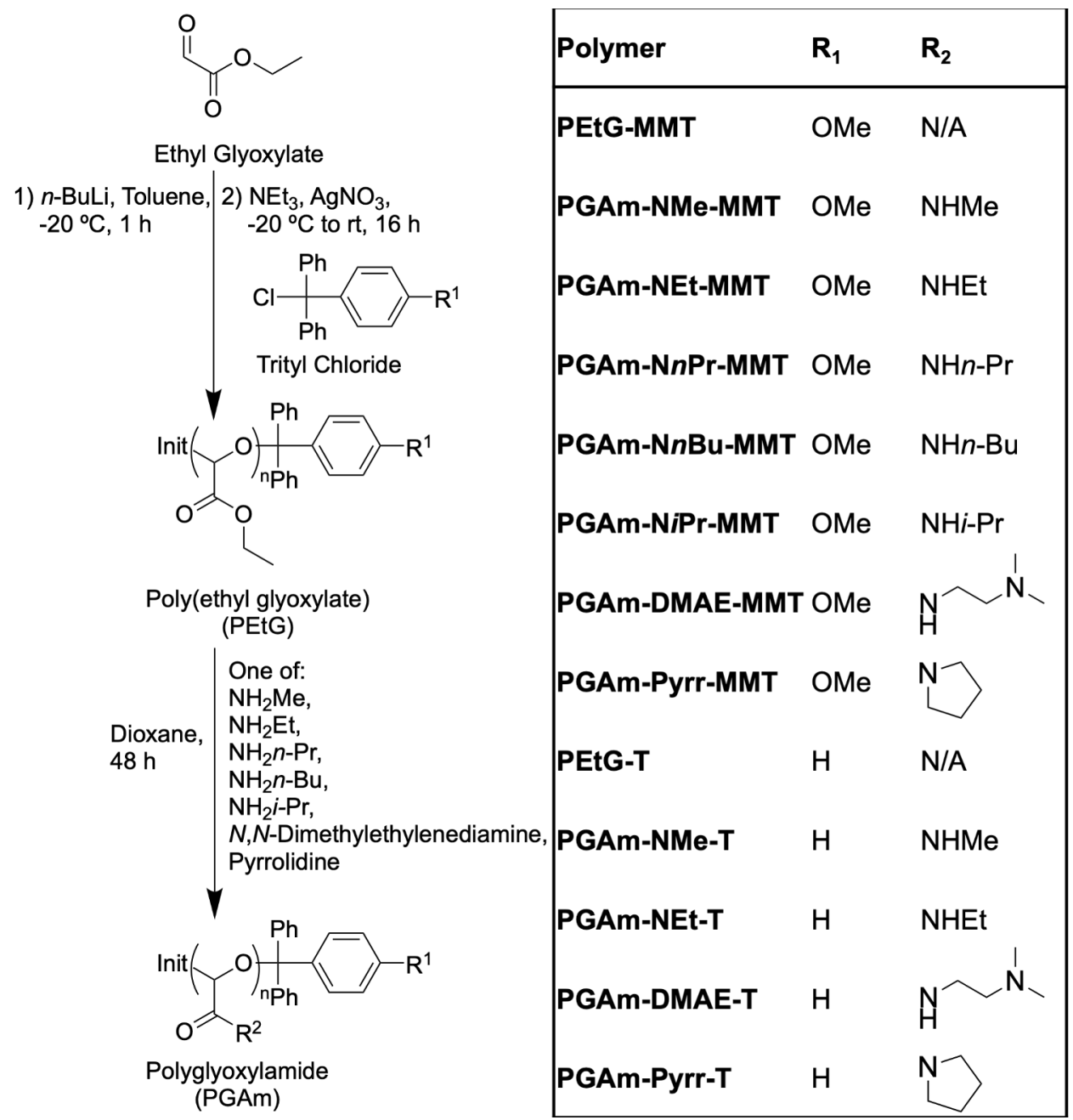

Scheme 2. Synthesis of PGAms (MMT = 4-monomethoxytrityl, T = trityl).

Synthesis of 4-Monomethoxytrityl End-Capped Polyglyoxylamides (PGAm-MMTs). To perform the post-polymerization modification, PEtG-MMT was dissolved in dry 1,4-dioxane, then reacted with a 5-fold molar excess of amine for $48 \mathrm{~h}$ to afford the corresponding PGAmMMT (Scheme 2). Different primary amines including methylamine, ethylamine, $n$-propylamine, $n$-butylamine, and isopropylamine were used to investigate basic structure-property relationships among simple PGAms. Pyrrolidine was used as a secondary amine. Other secondary amines such as dimethylamine and diethylamine were also investigated in preliminary work but led to 
incomplete conversion, suggesting that the ring structure of pyrrolidine is important for its reactivity. $N, N$-Dimethylethylenediamine was selected to introduce pendant $\mathrm{pH}$-sensitive tertiary amine groups to the polymer. The polymers were first isolated by the removal of the volatile amines, ethanol, and solvent from the reaction mixtures under vacuum. The crude polymer residues were subsequently dissolved in minimal $\mathrm{CH}_{2} \mathrm{Cl}_{2}$ and precipitated in $n$-pentane. Decanting off the liquid and drying the precipitate under vacuum afforded the purified polymers.

The purified polymers were characterized by ${ }^{1} \mathrm{H}$ NMR, ${ }^{13} \mathrm{C}$ NMR, and FT-IR spectroscopy to confirm that complete conversion to the amides had occurred (Figures S2-S8, S16-S22). Comparison of the ${ }^{1} \mathrm{H}$ NMR spectrum of PEtG-MMT to spectra of the PGAm-MMTs revealed several key differences (Figure 2). First, the peak corresponding to the backbone methine protons changed from a sharp multiplet at $\delta \sim 5.6 \mathrm{ppm}$ in PEtG-MMT into a broad singlet in the PGAmMMTs. In addition, the peaks corresponding to the ester $\mathrm{CH}_{2}$ and $\mathrm{CH}_{3}$ protons at $\delta 4.21$ and 1.28 ppm respectively disappeared and new peaks corresponding to the functional groups on the amide appeared. For example, in the spectrum of PGAm-NEt-MMT, two new peaks at $\delta 3.25$ and 1.13 ppm corresponding to the amide $\mathrm{CH}_{2}$ and $\mathrm{CH}_{3}$ protons respectively were observed. Finally, in all cases except for PGAm-Pyrr-MMT (tertiary amide), a broad multiplet appeared within the range of 7.50-9.50 ppm corresponding to the NH protons of the amide pendant groups. In the FT-IR spectra (Figure S29) the PGAm-MMTs had a characteristic $\mathrm{C}=\mathrm{O}$ amide stretch at $\sim 1650 \mathrm{~cm}^{-1}$, in contrast with PEtG-MMT, which had a characteristic $\mathrm{C}=\mathrm{O}$ ester stretch at $\sim 1750 \mathrm{~cm}^{-1}$. In addition, PGAm-MMTs synthesized from primary amines had peaks at $\sim 3200 \mathrm{~cm}^{-1}$ corresponding to the $\mathrm{N}-\mathrm{H}$ stretch of the amide pendant groups. 


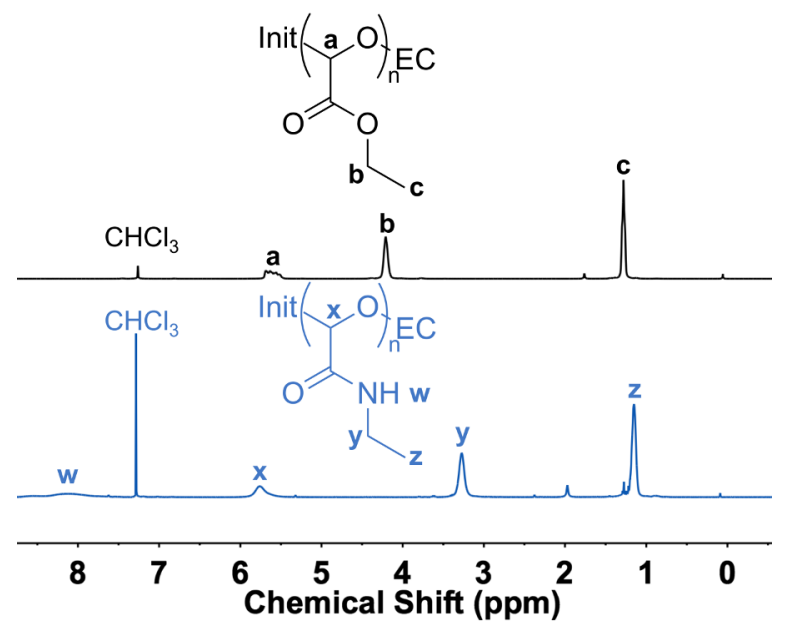

Figure 2. Comparison of the ${ }^{1} \mathrm{H}$ NMR spectra of PEtG-MMT (top) and PGAm-NEt-MMT (bottom) $\left(\mathrm{CDCl}_{3}, 400 \mathrm{MHz}\right)$.

While spectral data confirmed successful conversion of the pendant esters to amides, SEC analysis was used to compare the sizes of the polymers (Figure 3). As discussed above, postpolymerization modification of PEtG-MMT from the same batch of polymer has the advantage of creating different polymers with the same $\mathrm{DP}_{\mathrm{n}}$ and distribution of chain lengths. Indeed, all of the polymers, including PEtG-MMT, had similar $\oslash$ values (Table 1). Furthermore, most of the polymers had very similar $\mathrm{M}_{\mathrm{n}} \mathrm{s}$ of $\sim 60 \mathrm{~kg} / \mathrm{mol}$. The exception to this was PGAm-Pyrr-MMT, which had a measured $\mathrm{M}_{\mathrm{n}}$ of $27.4 \mathrm{~kg} / \mathrm{mol}$. It is likely that PGAm-Pyrr-MMT has a smaller hydrodynamic volume in the DMF eluent than the rest of the polymers, which may relate to its unique tertiary amide structure. To confirm this, multi-angle laser light scattering (MALLS) was used with SEC to obtain the absolute molar masses of PEtG-MMT and PGAm-Pyrr-MMT (Table 1). In contrast to SEC, this MALLS analysis revealed the expected higher $\mathrm{M}_{\mathrm{n}}$ for PGAmPyrr-MMT relative to the precursor polymer PEtG-MMT. Overall, spectral and SEC analyses confirmed that the post-polymerization modification of PEtG to form various PGAms via amidation is an easy and practical synthetic approach that does not cause significant polymer 
degradation. Regarding solubility, three of the polymers (PGAm-NMe-MMT, PGAm-DMAEMMT, and PGAm-Pyrr-MMT) were water-soluble at room temperature. This may provide access to different applications than polyglyoxylates, all of which so far have been waterinsoluble. ${ }^{17,32,39,41-42}$

Table 1. Summary of the physical and thermal properties of the 4-monomethoxytrityl end-capped polymers. For the SEC results, the values in parentheses were determined using MALLS rather than conventional calibration.

\begin{tabular}{|l|lll|ll|l|}
\hline Polymer & $\begin{array}{l}\mathbf{M}_{\mathbf{n}} \\
(\mathbf{k g} / \mathbf{m o l})\end{array}$ & $\begin{array}{l}\mathbf{M}_{\mathbf{w}} \\
\mathbf{( k g} / \mathbf{m o l})\end{array}$ & $\boldsymbol{D}$ & $\begin{array}{l}\mathbf{T}_{\mathbf{o}} \\
\left({ }^{\circ} \mathbf{C}\right)\end{array}$ & $\begin{array}{c}\mathbf{T}_{\mathbf{g}} \\
\left({ }^{\circ} \mathbf{C}\right)\end{array}$ & $\begin{array}{l}\text { Water- } \\
\text { Soluble }\end{array}$ \\
\hline PEtG-MMT & $51.8(43.2)$ & $73.6(67.0)$ & $1.4(1.6)$ & 170 & -10 & No \\
PGAm-NMe-MMT & 54.1 & 77.6 & 1.4 & 133 & 90 & Yes \\
PGAm-NEt-MMT & 56.7 & 83.7 & 1.5 & 137 & 85 & No \\
PGAm-NnPr-MMT & 62.4 & 92.8 & 1.5 & 136 & 68 & No \\
PGAm-NnBu-MMT & 54.2 & 78.2 & 1.4 & 148 & 58 & No \\
PGAm-NiPr-MMT & 73.6 & 99.2 & 1.3 & 130 & ${ }^{a} \mathrm{ND}$ & No \\
PGAm-DMAE-MMT & 60.0 & 89.2 & 1.5 & 141 & 39 & Yes \\
PGAm-Pyrr-MMT & $27.4(62.6)$ & $47.3(88.1)$ & $1.7(1.4)$ & 163 & 78 & Yes \\
\hline
\end{tabular}

${ }^{a}$ Not detected within the range of the measurement $\left(0-100{ }^{\circ} \mathrm{C}\right) ;{ }^{b}$ At ambient temperature 


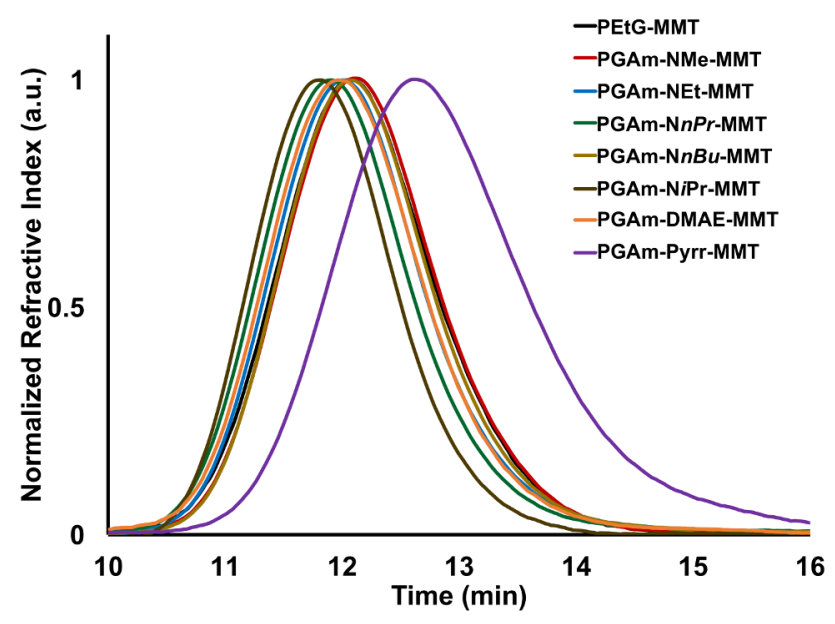

Figure 3. Overlay of the size exclusion chromatograms of the 4-monomethoxytrityl end-capped polymers.

Thermal Analysis of PGAm-MMTs. The thermal properties of the PGAm-MMTs were studied by TGA and differential scanning calorimetry (DSC). Based on TGA, the onset degradation temperatures $\left(\mathrm{T}_{\mathrm{o}}\right)$ were at least $130^{\circ} \mathrm{C}$ for all of the polymers (Table 1 and Figure S33). In addition, all of the PGAm-MMTs underwent multi-step degradations in contrast to the one-step degradation of PEtG-MMT. This may relate to the varying volatilities and degradation pathways for the glyoxylamide depolymerization products in comparison with ethyl glyoxylate, which can readily evaporate above PEtG's $\mathrm{T}_{0}$. DSC was performed up to $100-115^{\circ} \mathrm{C}$, depending on the polymer, ensuring that the maximum temperature was at least $30^{\circ} \mathrm{C}$ less than the $\mathrm{T}_{\mathrm{o}}$. Notably, the $\mathrm{T}_{\mathrm{g}} \mathrm{s}$ of all of the PGAm-MMTs evaluated were much higher than that of PEtG-MMT (Table 1, Figures S36-S43). These higher $\mathrm{T}_{\mathrm{g}}$ values likely result from structural features introduced by the amide pendant groups that hinder the movement of the polymer chains. For example, all of the PGAms with secondary amide pendant groups possess $\mathrm{NH}$ moieties that can participate in hydrogen bonding. Hydrogen bonding between polymer chains would hinder segmental motion, thus increasing the $\mathrm{T}_{\mathrm{g}}$. In addition, all of the PGAm pendant amide groups possess a $\mathrm{C}=\mathrm{N}$ resonance 
structure. The $\mathrm{C}=\mathrm{N}$ bond contributes rigidity to the polymer pendant groups. Finally, polymers with more compact and rigid pendant groups (PGAm-Pyrr-MMT and PGAm-NiPr-MMT) have decreased segmental motion. PEtG-NiPr-MMT in particular possesses all three of the aforementioned factors. This polymer was solid at all temperatures that could be investigated by DSC, suggesting its $\mathrm{T}_{\mathrm{g}}$ was greater than $100^{\circ} \mathrm{C}$. In general, the increased $\mathrm{T}_{\mathrm{g}}$ values of the PGAms made them glassy solids at room temperature. None of the above PGAms showed evidence of crystallization or melting in the evaluated temperature range, suggesting that they were amorphous like the polyglyoxylates. To exclude the possibility of melting temperatures outside the measured temperature range, powder x-ray diffraction was performed on the polymers. No sharp peaks attributable to the polymers were observed, confirming their amorphous structures (Figures S51S57).

Triggered Depolymerization of PGAm-MMTs. To assess if the PGAms retained the stimuliresponsive depolymerization feature of polyglyoxylates, depolymerization experiments were performed. Their depolymerization was studied by ${ }^{1} \mathrm{H}$ NMR spectroscopy in the absence and presence of $0.9 \mathrm{M}$ acetic acid as a trigger. The percent depolymerization was quantified based on the relative integrations of the peak at $\sim 5.5-5.6 \mathrm{ppm}$ corresponding to polymer backbone methine protons and the peak at $\sim 5.0-5.3 \mathrm{ppm}$ corresponding to the methine proton of the monomer hydrate depolymerization product (Figures 4a, S60-S71). PGAm-NEt-MMT, PGAm-NnPr-MMT, PGAm-NiPr-MMT, and PGAm-Pyrr-MMT were studied in 9:1 $\mathrm{CD}_{3} \mathrm{CN}: \mathrm{D}_{2} \mathrm{O}$, a solvent mixture that we have previously used to study the depolymerization of polyglyoxylates, including PEtGMMT. ${ }^{17,25}$ The other PGAm-MMTs were not soluble in this solvent system. In the presence of acetic acid, PGAm-Pyrr-MMT underwent complete depolymerization over a period of 30-35 
days, with $\sim 10$ days required for $50 \%$ depolymerization, a rate very similar to that reported for PEtG-MMT (Figure 4b) ${ }^{25}$ Interestingly, PGAm-NEt-MMT, PGAm-NnPr-MMT, and PGAmNiPr-MMT all underwent depolymerization much more rapidly, with depolymerization complete in 10-14 days and only $\sim 3$ days required for $50 \%$ depolymerization. The differentiating feature of these PGAms is their ability to hydrogen bond through their amide NH groups. We postulate that intramolecular hydrogen bonding between the oxygen adjacent to the end-cap and the final amide repeat unit can accelerate the cleavage of the end-cap on the polymer during depolymerization (Scheme 3). Such an intramolecular interaction should be favourable since the resulting hydrogen bond creates a five-membered ring. In the absence of acetic acid, all of the PGAms depolymerized much more slowly, with only $\sim 20 \%$ depolymerization observed for PGAm-NEt-MMT, PGAmNnPr-MMT, and PGAm-NiPr-MMT and only 4\% for PGAm-Pyrr-MMT. Thus, these data support that PGAms undergo depolymerization in response to stimuli, confirming their selfimmolative properties. In addition, the data highlight that structural features influence the depolymerization rate. 
a)
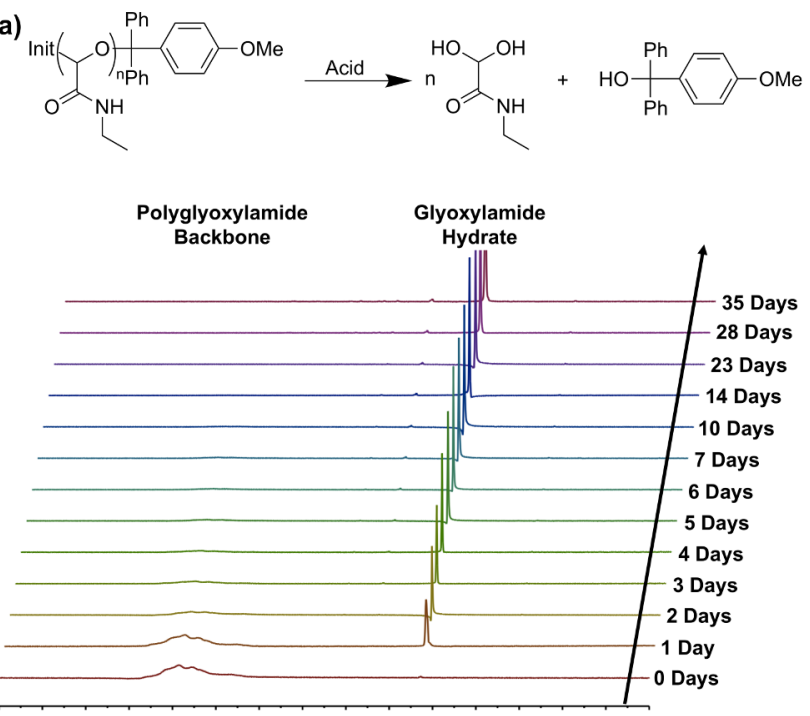

$\begin{array}{llllllllllllllll}.0 & 5.9 & 5.8 & 5.7 & 5.6 & 5.5 & 5.4 & 5.3 & 5.2 & 5.1 & 5.0 & 4.9 & 4.8 & 4.7 & 4.6 & 4.5\end{array}$

b)

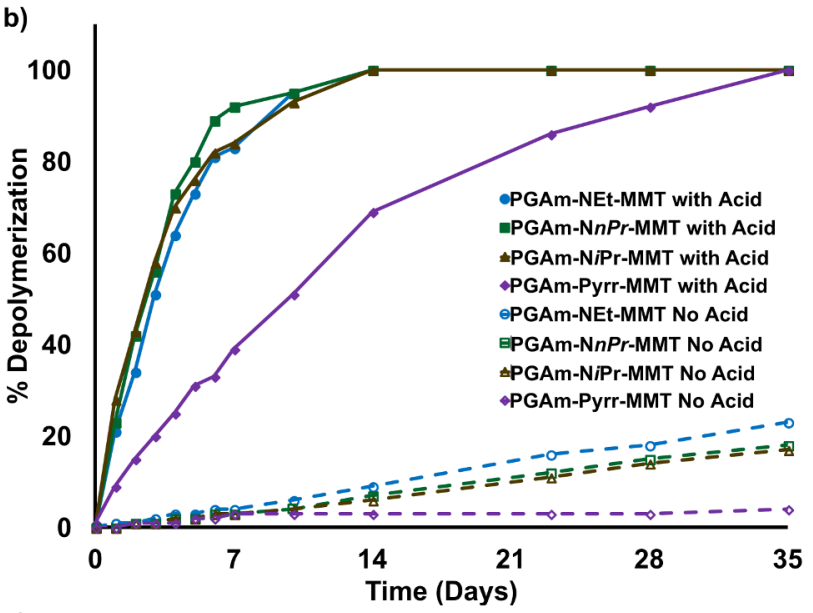

c)

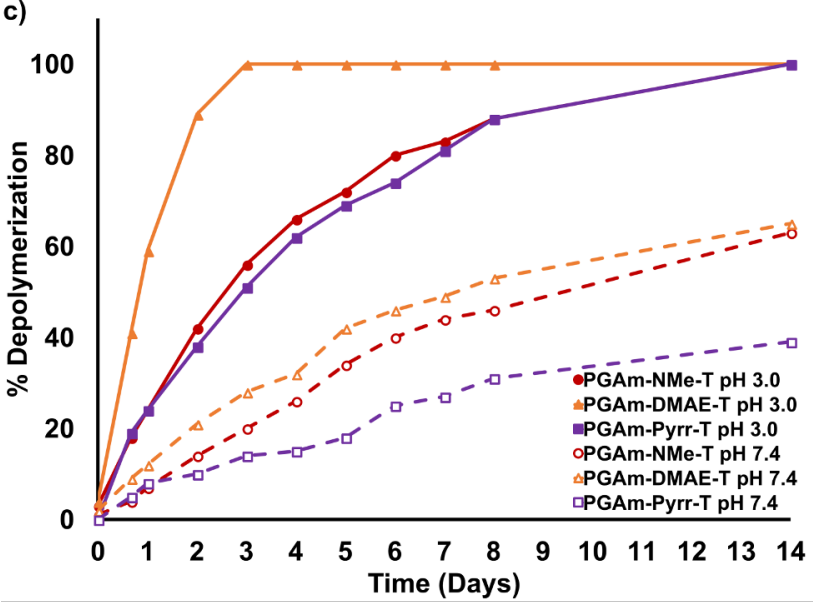

Figure 4. (a) Depolymerization of PGAm-NEt-MMT in 9:1 acetonitrile:water (0.1 M, pH 3.0) as a representative sample of how depolymerization was monitored using ${ }^{1} \mathrm{H}$ NMR spectroscopy 
$\left(\mathrm{CD}_{3} \mathrm{CN}, 400 \mathrm{MHz}\right)$. As depolymerization proceeds, there is a decrease in the backbone methine proton peak at $\sim 5.6 \mathrm{ppm}$ and an increase in the methine proton peak of the monomer hydrate at 5.0 ppm in the NMR spectra; (b) Depolymerization rates for selected PGAm-MMTs in 9:1 $\mathrm{CD}_{3} \mathrm{CN}: \mathrm{D}_{2} \mathrm{O}$ with and without acetic acid $(0.9 \mathrm{M})$ as a stimulus; (c) Depolymerization rates for selected PGAm-Ts in either citrate-buffered $\mathrm{D}_{2} \mathrm{O}(0.1 \mathrm{M}, \mathrm{pH} 3.0)$ or phosphate-buffered $\mathrm{D}_{2} \mathrm{O}(0.1$ M, pH 7.4).
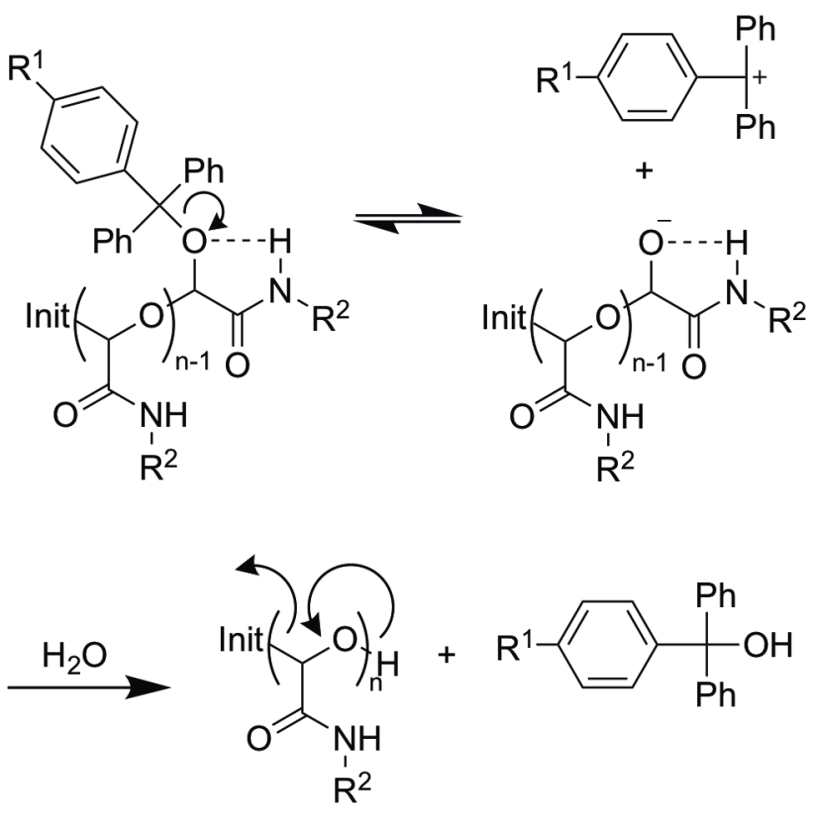

$\mathrm{R}^{1}=\mathrm{H}, \mathrm{OMe}$

$\mathrm{R}^{2}=\mathrm{Alkyl}$

Scheme 3. Hypothesized hydrogen bonding mechanism that assists with the removal of the trityl end-cap. The glyoxylamide repeating unit adjacent to the end-cap is able to form a five-membered ring, accelerating the removal of the end-cap. If water is present, the end-cap is trapped and the polymer begins to depolymerize. 
The high hydrophilicity of PEtG-NMe-MMT and PEtG-DMAE-MMT allowed their depolymerization to be studied in 9:1 $\mathrm{D}_{2} \mathrm{O}: \mathrm{CD}_{3} \mathrm{CN}$. Depolymerization was much faster in this solvent system, likely because the more polar, protic solvent accelerates the rate of cleavage of the 4-monomethoxytrityl end-cap, which follows an $\mathrm{S}_{\mathrm{N}} 1$ mechanism. Depolymerization in the presence of acetic acid was complete for both polymers in less than $24 \mathrm{~h}$ (Figure S58). Unfortunately, the polymers were also rapidly degraded in the absence of acid, indicating a lack of end-cap stability in the 9:1 $\mathrm{D}_{2} \mathrm{O}: \mathrm{CD}_{3} \mathrm{CN}$ solution. Because we wanted to further investigate the water-soluble PGAms (Table 1), this rapid background degradation in the absence of stimuli was problematic. Thus, more stable end-capped PGAms were required.

Synthesis of Trityl End-Capped Polyglyoxylamides (PGAm-Ts). To address the stability issue, we synthesized a series of new PGAms with a trityl end-cap instead of a 4-monomethoxytrityl end-cap. Since the simple trityl lacks the methoxy electron donating group, it is less labile than 4monomethoxytrityl. First, a new polyglyoxylate (PEtG-T) was synthesized with the trityl end-cap by the method described above (Scheme 2). ${ }^{1} \mathrm{H}$ NMR, ${ }^{13} \mathrm{C}$ NMR, and FT-IR spectroscopy were used to characterize the structure of PEtG-T (Figures S9 and S23). Both ${ }^{1} \mathrm{H}$ NMR spectroscopy and SEC suggested an $M_{n}$ of $\sim 9-10 \mathrm{~kg} / \mathrm{mol}$, while SEC provided a $Ð$ of 1.5 . The molar mass of PEtG-T is likely lower than that of the analogous PEtG-MMT because trityl chloride reacts more slowly than 4-monomethoxytrityl chloride. Because of this, we suspect that end-capping of the polymer chains occurred at a higher temperature, allowing the chains to partially depolymerize before being end-capped and stabilized. To confirm that the discrepancy between the molar masses of PEtG-MMT and PEtG-T was caused by the end-caps used rather than other factors such as monomer purity, in an additional experiment PEtG was synthesized from the one batch of 
monomer and capped with each end-cap. The resulting crude polymer mixtures were compared using SEC in tetrahydrofuran (THF) with PMMA standards (Figure S32), revealing that PEtG with 4-monomethoxytrityl as the end-cap had a larger $\mathrm{M}_{\mathrm{n}}(16.5 \mathrm{~kg} / \mathrm{mol})$ than PEtG with trityl as the end-cap $(6.8 \mathrm{~kg} / \mathrm{mol})$.

A subset of the PGAms (PGAm-NMe-T, PGAm-NEt-T, PGAm-DMAE-T, and PGAmPyrr-T) were synthesized from PEtG-T by reaction with the corresponding amines as described above (Scheme 2). ${ }^{1} \mathrm{H}$ NMR, ${ }^{13} \mathrm{C}$ NMR, and FT-IR spectroscopy were used to confirm complete conversion of the pendant esters to amides (Figures S10-S13, S24-S27). SEC analysis was also performed for each PGAm (Table 2). Again, PGAm-Pyrr-T had a lower $\mathrm{M}_{\mathrm{n}}$ than the other PGAms based on SEC (Figure S30). However, because of the lower $\mathrm{DP}_{\mathrm{n}}$ of this polymer series, it was possible to perform end-group analysis based on ${ }^{1} \mathrm{H}$ NMR spectroscopy (Table 2). This analysis confirmed that PEtG-T and all of the PGAm-Ts had very similar $\mathrm{DP}_{\mathrm{n}} \mathrm{s}$ and that this was not altered in the amidation reaction. Additionally, MALLS was used with SEC to acquire the absolute molar masses of both PEtG-T and PGAm-Pyrr-T (Table 2). While this analysis gave slightly different values than those acquired from ${ }^{1} \mathrm{H}$ NMR spectroscopy, it confirmed that PGAm-Pyrr-T had the expected higher $M_{n}$ relative to the precursor polymer PEtG-T. Thus, the lower SEC $M_{n}$ for PGAm-Pyrr-T was due to conformational differences with the other polymers. Additionally, the PGAm-Ts were investigated using TGA and DSC (Table 2). TGA revealed an increase in the $T_{o}$ values for trityl end-capped polymers relative to the 4-monomethoxytrityl end-capped polymers (Figure S34). The increase in thermal stability of the polymers corresponds to the reduced lability of the trityl end-cap in comparison to its 4-monomethoxytrityl analogue. ${ }^{38}$ DSC revealed a decrease in the $T_{g}$ values of the PGAm-Ts relative to their PGAm-MMT analogues (Table 2, 
Figures S44-S48). As the $\mathrm{T}_{\mathrm{g}}$ values of polymers are known to increase with their molar mass, ${ }^{46}$ the decrease in the $\mathrm{T}_{\mathrm{g}}$ values is consistent with the lower molar masses of the PGAm-Ts.

Table 2. Summary of the physical and thermal properties of the trityl end-capped polymers. For the SEC results, the values in parentheses were determined using MALLS rather than conventional calibration.

\begin{tabular}{|c|c|c|c|c|c|c|c|}
\hline Polymer & $\begin{array}{l}{ }^{1} \mathbf{H ~ Y} \\
\mathbf{D P}_{\mathbf{n}}\end{array}$ & $\begin{array}{l}\text { MR } \\
M_{n} \\
(\mathrm{~kg} / \mathrm{mol})\end{array}$ & $\begin{array}{l}\text { SEC } \\
M_{n}(\mathrm{~kg} / \mathrm{mol})\end{array}$ & $M_{w}(\mathrm{~kg} / \mathrm{mol})$ & $\boldsymbol{\oplus}$ & $\begin{array}{l}\mathrm{T}_{\mathrm{o}} \\
\left({ }^{\circ} \mathrm{C}\right)\end{array}$ & $\begin{array}{l}\mathbf{T}_{\mathrm{g}} \\
\left({ }^{\circ} \mathrm{C}\right)\end{array}$ \\
\hline PEtG-T & 90 & 9.7 & $8.8(14.4)$ & $13.5(18.6)$ & $1.5(1.3)$ & 206 & -3 \\
\hline PGAm-NMe-T & 83 & 7.7 & 8.4 & 14.6 & 1.7 & 172 & 70 \\
\hline PGAm-NEt-T & 89 & 9.5 & 8.2 & 14.9 & 1.8 & 161 & 76 \\
\hline PGAm-DMAE-T & 91 & 13.6 & 9.3 & 14.4 & 1.6 & 154 & 26 \\
\hline PGAm-Pyrr-T & 96 & 12.7 & $4.0(16.4)$ & $9.8(21.9)$ & $2.4(1.3)$ & 169 & 59 \\
\hline
\end{tabular}

Triggered Depolymerization of PGAm-Ts. The depolymerizations of PGAm-NMe-T, PGAm-

DMAE-T, and PGAm-Pyrr-T were studied by ${ }^{1} \mathrm{H}$ NMR spectroscopy in citrate-buffered $\mathrm{D}_{2} \mathrm{O}$ (0.1 M, pH 3.0) and phosphate-buffered $\mathrm{D}_{2} \mathrm{O}(0.1 \mathrm{M}, \mathrm{pH} 7.4)$ over a 14-day period at room temperature (Figures S72-S77). PGAm-NEt-T could not be studied under these conditions because it is insoluble in aqueous solutions at room temperature. Interestingly, PGAm-DMAE-T depolymerized more rapidly than the other polymers, with $50 \%$ depolymerization in $\sim 24 \mathrm{~h}$ at $\mathrm{pH}$ 3.0 and complete depolymerization within 3 days (Figure 4c). PGAm-NMe-T and PGAm-PyrrT reached 50\% depolymerization in $\sim 3$ days and required 10-14 days for complete 
depolymerization at $\mathrm{pH}$ 3.0. At $\mathrm{pH}$ 7.4, the studied PGAm-Ts underwent depolymerization at a much slower rate than at $\mathrm{pH} 3.0$, confirming their stimuli-responsive behavior. They underwent $\sim 30-60 \%$ depolymerization over 14 days, which demonstrates a stability improvement over the PGAm-MMTs discussed above. It is anticipated that increased long-term stability could be achieved through the use of different end-caps such as benzyl ether derivatives.

\section{Synthesis and Characterization of a Degradable Graft Copolymer Analogue of PEG.} POEGMA is a graft copolymer version of PEG comprising OEG side chains on a methacrylate backbone. It possesses properties similar to those of PEG, including the ability to shield conjugated biomolecules from degradation or clearance. ${ }^{43}$ However, POEGMA is inherently non-degradable, which may ultimately limit its applications in areas such as drug delivery. As demonstrated above, PGAms possess an acetal backbone that can undergo depolymerization. If this acetal backbone could be used to replace the methacrylate backbone of POEGMA, the resulting polymer should possess similar properties to POEGMA while at the same time undergo depolymerization when triggered by stimuli. Because the post-polymerization modification of PEtG to different PGAms with small molecule amines allowed for quantitative conversion, it was anticipated that it should be possible to graft amine-modified OEG chains to the acetal backbone.

To synthesize the graft copolymer, PEtG-T was dissolved in 1,4-dioxane with methoxypoly(ethylene glycol) amine (OEG-NH2) (Scheme 4). We found that the use of 1.0 stoichiometric equivalent of $\mathbf{O E G}-\mathbf{N H}_{2}$ per pendant ester instead of an excess for this reaction led to easier purification of the final graft copolymer (PGAm-OEG-T). However, in comparison with the amidation reactions involving small molecules, the use of fewer molar equivalents combined with steric hindrance associated with the relatively large OEG-NH2 resulted in slow conversion 
of the PEtG-T ester pendant groups to amides. To drive the reaction, it was heated in a pressure tube at $60{ }^{\circ} \mathrm{C}$ for 9 days. The resulting polymer was purified by multiple precipitations in $\mathrm{Et}_{2} \mathrm{O}$.

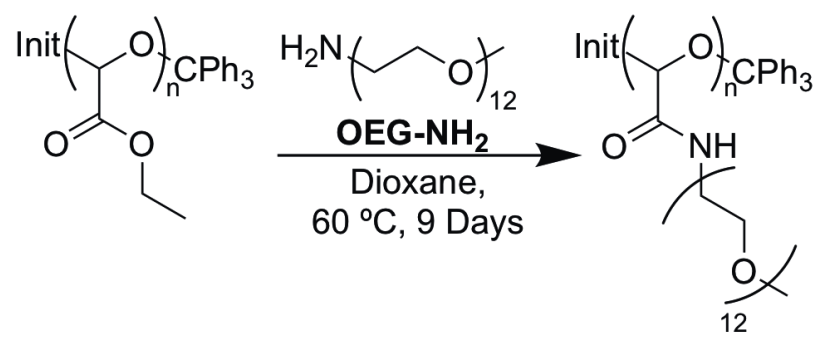

PEtG-T

PGAm-OEG-T

Scheme 4. Synthesis of PGAm-OEG-T.

PGAm-OEG-T was characterized by ${ }^{1} \mathrm{H}$ NMR, ${ }^{13} \mathrm{C}$ NMR, and FT-IR spectroscopy to confirm that conversion was complete (Figures S14 and S28). SEC of the polymer revealed a single peak, confirming residual $\mathbf{O E G}-\mathbf{N H}_{2}$ was removed during purification (Figure S31). The $\mathrm{M}_{\mathrm{n}}$ of the polymer was $58.5 \mathrm{~kg} / \mathrm{mol}$ while the $\oslash$ was 1.7 , very similar to the $\mathrm{M}_{\mathrm{n}}$ of $54.7 \mathrm{~kg} / \mathrm{mol}$ expected based on ${ }^{1} \mathrm{H}$ NMR spectroscopic analysis. Additionally, PGAm-OEG-T was analyzed via TGA and DSC (Figures S35 and S49). TGA revealed a $\mathrm{T}_{\mathrm{o}}$ of $339^{\circ} \mathrm{C}$, suggesting much higher thermal stability for this OEG graft copolymer than for the other PGAm-Ts and previously reported polyglyoxylates with various end-caps. ${ }^{17,25}$ The increase in thermal stability may be due to the high stability and low volatility of the OEG pendant groups as well as their ability to shield the end-cap and the acetal backbone of the main chain from thermal degradation. DSC of the polymer revealed a $T_{m}$ of $23{ }^{\circ} \mathrm{C}$, a property conferred by the OEG side chains. No $T_{g}$ was observed for the polymer over the temperature range from -70 to $200{ }^{\circ} \mathrm{C}$. Like POEGMA, PGAm-OEG-T is highly water-soluble. 
The degradation of PGAm-OEG-T in citrate-buffered $\mathrm{D}_{2} \mathrm{O}(0.1 \mathrm{M}, \mathrm{pH} 3.0)$ and phosphatebuffered $\mathrm{D}_{2} \mathrm{O}(0.1 \mathrm{M}, \mathrm{pH} 7.4)$ was first examined by ${ }^{1} \mathrm{H}$ NMR spectroscopy (Figures $\mathrm{S} 78$ and $\left.\mathrm{S} 79\right)$. PGAm-OEG-T depolymerized much more slowly than the other PGAm-Ts, with $\sim 60 \%$ depolymerization after 7 weeks in the $\mathrm{pH} 3.0$ buffer and only $\sim 10 \%$ depolymerization in the $\mathrm{pH}$ 7.0 buffer over the same time period (Figure S59). While PGAm-OEG-T can potentially hydrogen bond to the trityl oxygen as illustrated in Scheme 3, it is possible that conformational preferences prevent it from doing so. The structure-dependent depolymerization rates of the PGAms are an interesting aspect that was not noted for polyglyoxylates. To further study the depolymerization, it was also monitored by aqueous SEC for 7 weeks (Figures S80 and S81). At $\mathrm{pH} 3.0$, the chromatograms showed a substantial decrease in the intensity of the polymer peak over this time period. At pH 7.4, only a small decrease in peak intensity was observed over the 7 weeks. These results indicate that the concentration of the polymer in solution was decreasing over time as the polymer depolymerized. The retention time did not increase in either case. This indicates that endcap cleavage was the rate limiting step and that depolymerization of PGAm-OEG-T occurred rapidly after end-cap cleavage.

\section{Conclusions}

We have demonstrated for the first time the synthesis of self-immolative PGAms. These polymers were synthesized via a simple post-polymerization amidation of PEtG under mild conditions. Complete conversion of the esters to amide groups was demonstrated while avoiding degradation of the polymers. This allowed for the preparation of a library of different PGAms from a single batch of PEtG for property comparisons. The PGAms had much higher $\mathrm{T}_{\mathrm{g}}$ values than polyglyoxylates, attributed to the rigidity and hydrogen-bonding capabilities of the pendant amide 
groups. We demonstrated that PGAms could be triggered to depolymerize, confirming their selfimmolative behavior. Furthermore, some of the PGAms were water-soluble, opening possibilities for their application in areas such as medicine. Finally, a PGAm analogue of POEGMA was synthesized and characterized, demonstrating that it is possible to easily prepare PGAm graft copolymers from amine-terminated oligomers, affording a new depolymerizable analogue of PEG. Their ease of synthesis and unique properties relative to other self-immolative polymers should make PGAms a promising new platform for applications.

\section{Associated Content}

\section{Supporting Information}

Additional experimental procedures, ${ }^{1} \mathrm{H}$ NMR, ${ }^{13} \mathrm{C}$ NMR, and FT-IR spectra, size-exclusion chromatograms, TGA and DSC thermograms, powder x-ray diffractograms, and additional depolymerization studies.

\section{Author Information}

\section{Corresponding Author}

* Elizabeth R. Gillies, egillie@uwo.ca

\section{Author Contributions}

The manuscript was written through contributions of all authors. All authors have given approval to the final version of the manuscript. 


\section{Funding Sources}

This work was funded by the Natural Sciences and Engineering Research Council of Canada

(Discovery Grant 2016-04636, Strategic Partnership Grant 478981, and Canadian Graduate Scholarship to Q. S.).

\section{Acknowledgements}

We thank Aneta Borecki for performing the SEC and powder x-ray diffraction analyses, Jarret P. MacDonald for performing the TGA and DSC analyses, and the Gilroy research group for the use of their IR and thermal analysis instrumentation.

\section{References}

(1) Cohen Stuart, M.; Huck, W. T. S.; Genzer, J.; Muller, M.; Ober, C.; Stamm, M.;

Sukhorukov, G. B.; Szieifer, I.; Trukruk, V. V.; Urban, M.; Winnik, F.; Zauscher, S.; Luzinov, I.; Minko, S. Emerging Applications of Stimuli-Responsive Polymer Materials. Nat. Mater. 2010, 9, 101-113.

(2) Reineke, T. M. Stimuli-Responsive Polymers for Biological Detection and Delivery. ACS Macro Lett. 2015, 5, 14-18.

(3) Wei, M.; Gao, Y.; Li, X.; Serpe, M. J. Stimuli-Responsive Polymers and Their Applications. Polym. Chem. 2017, 8, 127-143.

(4) Mura, S.; Nicolas, J.; Couvreur, P. Stimuli-Responsive Nanocarriers for Drug Delivery. Nat. Mater. 2013, 12, 991-1003. 
(5) Schild, H. G. Poly(N-Isopropylacrylamide): Experiment, Theory and Application. Prog. Polym. Sci. 1992, 17, 163-249.

(6) Yu, C.; Mutlu, S.; Selvaganapathy, P.; Mastrangelo, C. H.; Svec, F.; Fréchet, J. M. J. Flow Control Valves for Analytical Microfluidic Chips without Mechanical Parts Based on Thermally Responsive Monolithic Polymers. Anal. Chem. 2003, 75, 1958-1961.

(7) Qin, S. H.; Geng, Y.; Discher, D. E.; Yang, S. Temperature-Controlled Assembly and Release from Polymer Vesicles of Poly(ethylene oxide)-Block-Poly( $N$-isopropylacrylamide). Adv. Mater. 2006, 18, 2905-2909.

(8) Li, W.; Zhao, H.; Qian, W.; Li, H.; Zhang, L.; Ye, Z.; Zhang, G.; Xia, M.; Li, J.; Gao, J.;

Li, B.; Kou, G.; Dai, J.; Wang, H.; Guo, Y. Chemotherapy for Gastric Cancer by Finely Tailoring Anti-Her2 Anchored Dual Targeting Immunomicelles. Biomaterials 2012, 33, 53495362.

(9) Heffernan, M. J.; Murthy, N. Polyketal Nanoparticles: A New pH-Sensitive Biodegradable Drug Delivery Vehicle. Bioconjugate Chem. 2005, 16, 1340-1342.

(10) Rickerby, J.; Prabhakar, R.; Ali, M.; Knowles, J.; Brocchini, S. Water-Soluble Polyacetals Derived from Diphenols. J. Mater. Chem. 2005, 15, 1849-1856.

(11) Jain, R.; Standley, S. M.; Fréchet, J. M. J. Synthesis and Degradation of pH-Sensitive Linear Poly(amidoamine)s. Macromolecules 2007, 40, 452-457.

(12) Roth, M. E.; Green, O.; Gnaim, S.; Shabat, D. Dendritic, Oligomeric, and Polymeric SelfImmolative Molecular Amplification. Chem. Rev. 2016, 116, 1309-1352.

(13) Sagi, A.; Weinstain, R.; Karton, N.; Shabat, D. Self-Immolative Polymers. J. Am. Chem. Soc. 2008, 130, 5434-5435. 
(14) Dewit, M. A.; Gillies, E. R. A Cascade Biodegradable Polymer Based on Alternating Cyclization and Elimination Reactions. J. Am. Chem. Soc. 2009, 131, 18327-18334.

(15) Olah, M. G.; Robbins, J. S.; Baker, M. S.; Phillips, S. T. End-Capped Poly(benzyl ethers): Acid and Base Stable Polymers That Depolymerize Rapidly from Head-to-Tail in Response to Specific Applied Signals. Macromolecules 2013, 46, 5924-5928.

(16) Seo, W.; Phillips, S. T. Patterned Plastics That Change Physical Structure in Response to Applied Chemical Signals. J. Am. Chem. Soc. 2010, 132, 9234-9235.

(17) Fan, B.; Trant, J. F.; Wong, A. D.; Gillies, E. R. Polyglyoxylates: A Versatile Class of Triggerable Self-Immolative Polymers from Readily Accessible Monomers. J. Am. Chem. Soc. 2014, 136, 10116-10123.

(18) Dewit, M. A.; Beaton, A.; Gillies, E. R. A Reduction Sensitive Cascade Biodegradable Linear Polymer. J. Polym. Sci., Part A: Polym. Chem. 2010, 48, 3977-3985.

(19) Chen, E. K. Y.; McBride, R. A.; Gillies, E. R. Self-Immolative Polymers Containing Rapidly Cyclizing Spacers: Toward Rapid Depolymerization Rates. Macromolecules 2012, 45, 7364-7374.

(20) de Gracia Lux, C.; McFearin, C. L.; Joshi-Barr, S.; Sankaranarayanan, J.; Fomina, N.; Almutairi, A. A Single UV or Near IR Triggering Event Leads to Polymer Degradation into Small Molecules. ACS Macro Lett. 2012, 1, 922-926.

(21) Liu, G.; Wang, X.; Hu, J.; Zhang, G.; Liu, S. Self-Immolative Polymersomes for HighEfficiency Triggered Release and Programmed Enzymatic Reactions. J. Am. Chem. Soc. 2014, $136,7492-7497$.

(22) Peterson, G. I.; Church, D. C.; Yakelis, N. A.; Boydston, A. J. 1,2-Oxazine Linker as a Thermal Trigger for Self-Immolative Polymers. Polymer 2014, 55, 5980-5985. 
(23) Fan, B.; Trant, J. F.; Hemery, G.; Sandre, O.; Gillies, E. R. Thermo-Responsive SelfImmolative Nanoassemblies: Direct and Indirect Triggering. Chem. Commun. 2017, 53, 1206812071.

(24) Wong, A. D.; Güngör, T. M.; Gillies, E. R. Multiresponsive Azobenzene End-Cap for Self-Immolative Polymers. ACS Macro Lett. 2014, 3, 1191-1195.

(25) Fan, B.; Trant, J. F.; Gillies, E. R. End-Capping Strategies for Triggering End-to-End Depolymerization of Polyglyoxylates. Macromolecules 2016, 49, 9309-9319.

(26) Esser-Kahn, A. P.; Sottos, N. R.; White, S. R.; Moore, J. S. Programmable Microcapsules from Self-Immolative Polymers. J. Am. Chem. Soc. 2010, 132, 10266-10268.

(27) Weinstain, R.; Baran, P. S.; Shabat, D. Activity-Linked Labeling of Enzymes by SelfImmolative Polymers. Bioconjugate Chem. 2009, 20, 1783-1791.

(28) Feinberg, A. M.; Hernandez, H. L.; Plantz, C. L.; Mejia, E. B.; Sottos, N. R.; White, S. R.; Moore, J. S. Cyclic Poly(Phthalaldehyde):Thermoforming a Bulk Transient Material. ACS Macro Lett. 2017, 7, 47-52.

(29) DiLauro, A. M.; Abbaspourrad, A.; Weitz, D. A.; Phillips, S. T. Stimuli-Responsive Core-Shell Microcapsules with Tunable Rates of Release by Using a Depolymerizable Poly(Phthalaldehyde) Membrane. Macromolecules 2013, 46, 3309-3313.

(30) Fan, B.; Gillies, E. R. Poly(Ethyl Glyoxylate)-Poly(Ethylene Oxide) Nanoparticles: Stimuli-Responsive Drug Release Via End-to-End Polyglyoxylate Depolymerization. Mol. Pharmaceutics 2017, 14, 2548-2559.

(31) Gambles, M. T.; Fan, B.; Borecki, A.; Gillies, E. R. Hybrid Polyester Self-Immolative Polymer Nanoparticles for Controlled Drug Release. ACS Omega 2018, 3, 5002-5011. 
(32) Fan, B.; Yardley, R. E.; Trant, J. F.; Borecki, A.; Gillies, E. R. Tuning the Hydrophobic Cores of Self-Immolative Polyglyoxylate Assemblies. Polym. Chem. 2018, 9, 2601-2610.

(33) Zhang, H.; Yeung, K.; Robbins, J. S.; Pavlick, R. A.; Wu, M.; Liu, R.; Sen, A.; Phillips, S. T. Self-Powered Microscale Pumps Based on Analyte-Initiated Depolymerization Reactions. Angew. Chem. Int. Ed. 2012, 51, 2400-2404.

(34) Weinstain, R.; Sagi, A.; Karton, N.; Shabat, D. Self-Immolative Comb-Polymers: Multiple-Release of Side-Reporters by a Single Stimulus Event. Chem. Eur. J. 2008, 14, 68576861.

(35) Lewis, G. G.; Robbins, J. S.; Phillips, S. T. Phase-Switching Depolymerizable Poly(carbamate) Oligomers for Signal Amplification in Quantitative Time-Based Assays. Macromolecules 2013, 46, 5177-5183.

(36) Lewis, G. G.; Robbins, J. S.; Phillips, S. T. Point-of-Care Assay Platform for Quantifying Active Enzymes to Femtomolar Levels Using Measurements of Time as the Readout. Anal. Chem. 2013, 85, 10432-10439.

(37) Lewis, G. G.; Robbins, J. S.; Phillips, S. T. A Prototype Point-of-Use Assay for Measuring Heavy Metal Contamination in Water Using Time as a Quantitative Readout. Chem. Commun. 2014, 50, 5352-5354.

(38) Fan, B.; Salazar, R.; Gillies, E. R. Depolymerization of Trityl End-Capped Poly(ethyl glyoxylate): Potential Applications in Smart Packaging. Macro. Rapid Commun. 2018, 39, 1800173.

(39) Belloncle, B.; Bunel, C.; Menu-Bouaouiche, L.; Lesouhaitier, O.; Burel, F. Study of the Degradation of Poly(Ethyl Glyoxylate): Biodegradation, Toxicity and Ecotoxicity Assays. $J$. Polym. Environ. 2012, 20, 726-731. 
(40) Fan, B.; Trant, J. F.; Yardley, R. E.; Pickering, A. J.; Lagugné-Labarthet, F.; Gillies, E. R. Photocontrolled Degradation of Stimuli-Responsive Poly(ethyl glyoxylate): Differentiating Features and Traceless Ambient Depolymerization. Macromolecules 2016, 49, 7196-7203.

(41) Belloncle, B.; Burel, F.; Oulyadi, H.; Bunel, C. Study of the in Vitro Degradation of Poly(ethyl glyoxylate). Polym. Degrad. Stab. 2008, 93, 1151-1157.

(42) Kaitz, J. A.; Diesendruck, C. E.; Moore, J. S. Divergent Macrocyclization Mechanisms in the Cationic Initiated Polymerization of Ethyl Glyoxylate. Macromolecules 2014, 47, 3603-3607. (43) Liu, M.; Leroux, J.-C.; Gauthier, M. A. Conformation-Function Relationships for the Comb-Shaped Polymer Poegma. Prog. Polym. Sci. 2015, 48, 111-121.

(44) Gauthier, M. A.; Gibson, M. I.; Klok, H.-A. Synthesis of Functional Polymers by PostPolymerization Modification. Angew. Chem. Int. Ed. 2009, 48, 48-58.

(45) Rabiee Kenaree, A.; Gillies, E. R. Controlled Polymerization of Ethyl Glyoxylate Using Alkyllithium and Alkoxide Initiators. Macromolecules 2018, 51, 5501-5510.

(46) Fox, T. G.; Flory, P. J. Second-Order Transition Temperatures and Related Properties of Polystyrene. I. Influence of Molecular Weight. J. Appl. Phys. 1950, 21, 581-591. 